\title{
Article
}

\section{Body Part Removal: A Thematic Exploration of U.K. Homicide Offenses}

\author{
Almond, Louise, Pell, Connor and Mcmanus, Michelle Ann \\ Available at http://clok.uclan.ac.uk/25341/ \\ Almond, Louise, Pell, Connor and Mcmanus, Michelle Ann ORCID: 0000-0002- \\ 0095-1071 (2018) Body Part Removal: A Thematic Exploration of U.K. \\ Homicide Offenses. Journal of Interpersonal Violence. ISSN 0886-2605
}

It is advisable to refer to the publisher's version if you intend to cite from the work. http://dx.doi.org/10.1177/0886260518814268

For more information about UCLan's research in this area go to http://www.uclan.ac.uk/researchgroups/ and search for < name of research Group>.

For information about Research generally at UCLan please go to http://www.uclan.ac.uk/research/

All outputs in CLoK are protected by Intellectual Property Rights law, including Copyright law. Copyright, IPR and Moral Rights for the works on this site are retained by the individual authors and/or other copyright owners. Terms and conditions for use of this material are defined in the policies page.

\section{CLoK}

Central Lancashire online Knowledge www.clok.uclan.ac.uk

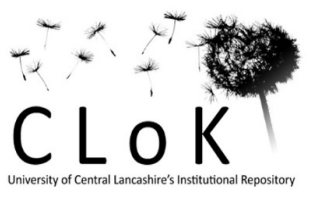




\title{
Body Part Removal: A Thematic Exploration of UK Homicide Offenses
}

\begin{abstract}
Body part removal (BPR) is a rare homicide phenomena which emerges as a result of a variety of motives. Fifty eight BPR UK homicide cases were analysed. Findings indicated key characteristics within BPR murder offenses, with most offender's male, aged around 31 years, knew their victims, with presence of alcohol, drugs and mental health issues and over two-thirds of sample had previous convictions, over $50 \%$ for theft. Offense behaviors showed 'multiple wounds' and 'victim naked' as highest frequency, with the head as the most frequently removed body part. Smallest space analysis (SSA) identified two behavioral themes (expressive and instrumental) with $62.1 \%$ of cases classified as one of these. The study has provided the largest UK sample of BPR homicide furthering understanding this type of offense and the offenders who commit it.
\end{abstract}

\section{Introduction}

Dismemberment of the victim or body part removal (BPR) in the course or aftermath of a homicide is a particularly disturbing, if infrequent, phenomenon. "Within this context, BPR has been acknowledged to occur at any point during or after an offense, and can emerge as the result of a variety of underlying motives (Rajs, Lundstrom, Broberg, Lidberg \& Lindquist, 1998).

BPR is rare in cases of homicide (Di Nunno, Costantinides, Vacca, \& Di Nunno, 2006). To illustrate, in the UK, 518 homicides occurred in the year ending March 2015 alone (Office for National Statistics; ONS, 2016), whereas only 55 cases of BPR were estimated to have occurred between 1975 and 2004 (Cox, 2006). This is an estimated average of two cases per year; with BPR occurring in approximately $0.4 \%$ of all homicides.

\section{Problems with BPR Research}

Despite attempts to delineate the phenomenon, at least two methodological shortcomings have limited the extent to which existing research can contribute to an 
externally valid understanding of BPR. First, the literature is over-saturated with medico-legal case reports (Häkkänen-Nyholm, Weizmann-Henelius, Salenius, Lindberg \& Repo-Tiihonen, 2009). This constitutes one of the weakest research designs available to scientists. Because of their descriptive nature and overreliance on small samples, they are difficult to generalise to the behaviour as a whole (Campbell \& Stanley, 1966). Second, researchers have relied on international data sources - with none having been conducted in the UK. Because definitions of homicide vary between countries, and because some countries do not routinely collect data on criminal mutilation (Konopka, Strona, Bolechala \& Kunz, 2007), these findings are difficult to apply to the UK directly (ONS, 2016). Together, this means that when faced with difficult-to-solve cases, the literature provides information of a limited value to support with the evidence-based decision making of British investigators (see Alison, Smith, Eastman \& Rainbow, 2003).

\section{BPR Offense Behaviors}

In general, case reports have focused on the unusual cases of BPR. For example, these have included cases of ritualistic dismemberment by medicine men (e.g. Scholtz, Phillips \& Knobel, 1997; Steyn, 2005; Bhootra \& Weiss, 2006) and suspected homicidal decapitation by chainsaw (e.g. Reuhl \& Bratzke, 1999). Although these studies may indicate that certain behaviors (e.g. decapitation) are more common than others (e.g. Türk, Püschel \& Tsokos, 2004); because of small samples and sensationalism, they can only provide little in the way of reliable frequency estimates. However, to the knowledge of the researcher, only one empirical studyies hasve been published that sheds light on this.

Using a representative sample of homicide offenses from Finland between 1995 and 2004, Häkkänen-Nyholm et al. (2009) compared the offense behaviors of 13 cases of homicide with mutilation against 663 without mutilation. The researchers found that in the former, offenders were more likely to use sharp weapons $(92.3 \%$ vs $57.3 \%$ ), victims' bodies were less likely to be found at the crime scene (46.2\% vs $89.0 \%$ ), sexual behaviour was more likely to have occurred (38.5\% vs $2.1 \%$ ), and cases were more likely to have involved at least two offenders (30.8\% vs $12.3 \%)$. However, despite reaching statistical significance, Häkkänen-Nyholm et al.'s findings demonstrated only small-to-moderate effect size and were based on non-UK data. 


\section{BPR Offender Characteristics}

As with the research on offense behaviors, few researchers have attempted to empirically investigate the background characteristics of BPR murderers (HäkkänenNyholm et al., 2009). Only two studies were found to have done so.

First, Ressler, Burgess, Hartman, Douglas \& McCormack (1986) compared the background characteristics of a sample of 12 sexual and 16 non-sexual murderers. The researchers found a "significant" association $(p=.07)$ between victim mutilation and sexual abuse in childhood and adolescence: abused offenders were more likely to mutilate their victims (67\% vs $44 \%)$. However, the alpha level used to denote significance in this study exceeded the traditional $p \leq .05$ of the behavioural sciences (Rosnow \& Rosenthal, 1989).

Most recently, Häkkänen-Nyholm et al. (2009) found six significant findings that distinguished mutilation murderers from other homicide offenders. Of the 13 for which an educational history was known, more mutilation murderers received special education (53.8\% vs $29.5 \%$ ). Of all 14 convicted offenders, more mutilation murderers received mental health contact prior to the age of 18 (50.0\% vs $24.1 \%)$ and had received inpatient mental health contact (71.4\% vs $40.0 \%)$. More had also exhibited self-destructive behaviour (64.3\% vs 38.0\%), and had received a diagnosis of schizophrenia (28.6\% vs $9.8 \%$ ) or organic brain disorder (28.6\% vs $9.3 \%$ ). However, in evaluation of all three studies; although they undoubtedly offer insight into the characteristics of BPR offenders, their findings should be treated with caution - none adjusted their alpha level to control for the effects of multiple comparisons (Bland \& Altman, 1995).

\section{Behavioural Classification Systems}

\section{'Expressive' and 'instrumental' homicide}

Based on Feshbach's (1964) seminal work, a distinction in the forensic literature has often been made between 'expressive' and 'instrumental' homicide. According to Salfati and Canter (1999), expressive homicide "occurs in response to angerinducing conditions such as insult, physical attack, or personal failures" (pp.393) cases in which the goal is to make the victim suffer. By comparison, instrumental 
homicide "comes through the desire for objects or the status possessed by another person" (pp.393) - cases where the goal is to obtain a desired object.

Traditionally, investigative psychologists have explored this typology using multidimensional scaling procedures (MDS) (e.g. smallest space analysis; SSA) (e.g. Salfati \& Canter, 1999; Salfati, 2000 and 2003; Salfati \& Haratsis, 2001; Santtila, Canter, Elfgren \& Häkkänen, 2001; Santtila, Häkkänen, Canter \& Elfgren, 2003). However, despite the large quantity of case reports on the topic, few MDS studies have considered BPR; and even in the rare cases in which they have, it has usually only been referred to peripherally.However, at least twostudies have included BPR as a single behavioural variable: Salfati and Haratsis' (2001) exploration of Greek Homicide, and Santtila et al.'s (2001 \& 2003) explorations of Finnish homicide. Inboth of these studies, BPR was interpreted as an expressive behaviour.

\section{Aims and Objectives}

Evidence-based reasoning is a core tenet of the recommendations provided to British police forces by Behavioural Investigative Advisors (BIAs) (Alison, Smith, Eastman \& Rainbow, 2003; Almond, Alison \& Porter, 2008). However, because mutilation in the context of homicide is rare (Rajs et al.,1998; Di Nunno et al., 2006; Konopka et al., 2007; Häkkänen-Nyholm et al., 2009), there are no MDS research publications which have considered mutilation and dismembermentA logical consequence of this is that when BIAs encounter a case of homicide involving body part removal, there are few empirical sources available to them from which they can draw and support investigative inferences. The proposed study will provide the first empirical piece of research based on UK mutilation homicide offenses from the ViCLAS database. This study will contribute to an understanding of BPRin cases of homicide. This will ultimately enable investigators to draw and support inferences about the behaviors and background characteristics of perpetrators of this often overlooked type of offense.

The purpose of the current study is twofold. First, it aimed to contribute a contemporary study of BPR to the insufficient and insubstantial research base. Second, it aimed to provide investigators in the UK with an empirically-tested 
framework to assist future investigations of BPR. In order to achieve these aims, the study proposed two objectives.

1. Provide base rate frequencies for BPR behaviors;

2. Conduct athematic exploration of BPR murder with a contemporary sample of offenses from the UK. In doing so, it was hypothesised that a thematic distinction between expressive and instrumental behaviors would emerge (Table 1).

\section{Methodology}

\section{Data and Sample}

The data were extracted from the Violent Crime Linkage Analysis System (ViCLAS) located at the National Crime Agency's Serious Crime Analysis Section (SCAS). This system was established in 1998 and includes standardised information from offenses across the United Kingdom. The selection criteria used to determine which cases were suitable for analysis were as follows:

- Cases were classified as murder

- Cases involved successful or attempted BPR

- Cases were solved or unsolved

- Solved cases included single or multiple offenders

- Cases occurred between 1975 and 2016

This brought the sample to 58 cases $^{1}$. The sample was comprised of 57 (98.3 $\%)$ single and 1 (1.7\%) multiple victim cases, and 42 (72.4\%) solved cases and 16 (27.6\%) unsolved cases. Of the solved cases, there were $36(85.7 \%)$ single and 6 (14.3\%) multiple offender cases.

\section{Statistical Procedure}

The study used secondary data based on the case papers of national police forces which had been subsequently coded by National Crime Agency's Serious Crime Analysis Section. It included variables related to offender and victim characteristics, and offense and post-offense behaviors. Most were coded dichotomously to indicate

\footnotetext{
${ }^{1} 44$ of these cases were originally examined in an unpublished University of Bath undergraduate dissertation by Cox, J (2006).
} 
the presence or absence of variables, the exception being offender and victim age and the number of offenders' previous convictions, which were coded at the ratio level. Statistical analysis took place in three stages.

\section{Stage I: Descriptive analysis}

Descriptive statistics were calculated for all variables: counts and frequencies for categorical data, and means and ranges for ratio data.

\section{Stage II: Smallest space analysis}

SSA (Lingoes, 1973) was used to thematically explore offense behaviors. The procedure is a non-metric MDS procedure based on the notion that the underlying structure of any construct can best be delineated by examining the interrelationship of relevant variables (Santtila et al., 2003).

As to avoid undue influence on the analysis, behaviors were only included if they were present in more than $5 \%$ and fewer than $80 \%$ of cases (Bonny, Almond \& Woolnough, 2016). Where behaviors were conceptually similar, they were condensed into a single variable. Mutually exclusive variables were also excluded. The most theoretically salient behaviors were retained whilst their mutually exclusive counterparts excluded, see Appendix for coding dictionary.

As outlined by Canter and Heritage (1990), the SSA procedure follows several steps. First association coefficients are computed between all variables. These give an indication of the degree of co-occurrence between each. Here, the Jaccard's association coefficient was used. This gives the proportion of co-occurrence between two dichotomous variables, the value of which does not increase in the presence of joint non-occurrences (Bonny et al, 2016). This was appropriate given that the data may have left the presence of some variables unmentioned (Santtila et al., 2001). Second, the procedure ranks the association coefficients and presents them in abstract space (Bonny et al., 2016). The resulting plot is configured to show that the closer points are on the plot, the greater the association between the variables that they represent (Guttman, 1968). Third, a coefficient of alienation (Borg \& Lingoes, 1987 ) is computed. This is a measure of the fit between the plot and the original 
matrix (Canter \& Heritage, 1990). A coefficient of less than 0.25 indicates an acceptable fit (Canter, Alison, Alison \& Wentink, 2004).

Once a plot had been produced, a straight line was manually drawn to bisect it where it most appropriately separated the behavioural variables. The position of the line was predominantly theory-driven; dividing the variables along the hypothesised themes (Table 1).

Stage III: Dominant theme analysis

If the SSA was successful, each of the 58 cases was then examined to see if they could be assigned to a dominant theme. A percentage score was calculated for each based on the number of expressive and instrumental behaviors that were present. Using the criterion developed by Salfati (2000), cases were assigned to a theme when the behaviors of one were at least twice as frequent (\%) as the behaviors of the other.

\section{Results}

\section{Descriptive Analysis}

Table 2 shows that most offenders were male (94.2\%) and White European (88.5\%). Their ages ranged from 15 to 52 years old, but most were between 26 and 40 years old at the time of offense $(51.9 \%)\left(M_{\text {male }}=31.57, S D_{\text {male }}=10.66 ; M_{\text {female }}=20.00\right.$, $\left.S D_{\text {female }}=3.61\right)$. Many were friends with their victim(s) $(42.3 \%)$, some were alcoholics (15.4\%), drug users (23.1\%), and/or mentally disabled (23.1\%), and most had a previous conviction (67.3\%). In the subsample of offenders with at least one previous conviction, the number of convictions ranged from 17 to $52\left(M_{\text {male }}=14.63\right.$, $S D_{\text {male }}=18.47 ; M_{\text {female }}=0.00, S D_{\text {female }}=0.00$ ).

Table 3 shows that in regards to previous convictions, theft $(60.0 \%)$ was the most common; aggravated burglary, bestiality, indecent assault, indecent exposure, kidnapping, manslaughter and rape were the least common (all 2.9\%). Table 4 shows that most victims were female (64.4\%) and White European (88.1\%). Their ages ranged from 4 to 91 years old but most were between 26 and 40 years old $(35.6 \%)\left(M_{\text {male }}=39.70, S D_{\text {male }}=22.71 ; M_{\text {female }}=33.03, S D_{\text {female }}=17.57\right)$.

The most frequent behaviors were 'multiple wounds (distributed)' (69.0\%) and 'victim naked' (67.2\%) (see Table 5). BPR-specific behaviors were generally less 
frequent than 'other' behaviors. The most frequently removed body part was the head $(48.3 \%)$ and the least frequently mutilated were the back, chest, eyes and shoulders (all 1.7\%). The most common method of removing body parts was by using unskilled cuts (50.0\%); the least by biting them off (1.7\%).

\section{Smallest Space Analysis}

A SSA was conducted using 26 offense behaviors across 58 cases of BPR murder. A coefficient of alienation of 12 was produced. This indicated a good degree of fit between the output and the original matrix. Figure 1 shows vectors 1 and 3 of the three-dimensional SSA. Each point represents an offense behaviour. The shorter the distance between two points, the more likely they were to have co-occurred.

Figure 1 shows how the co-occurrence of the behaviors could be split into two distinct regions, labelled 'expressive' and 'instrumental'. Using Cronbach's $\alpha$, these demonstrated moderate-to-high levels of internal reliability ( $\alpha_{\text {expressive }}=.66$ and $\alpha_{\text {instrumental }}=.67$ ). Table 5 shows the behavioural composition of each theme.

All except one of the offense behaviors fell in the region where they had been hypothesised to fall. However, 'multiple wounds (distributed)' (69.0\%), which had originally been expected to fall in the expressive theme, was found in the instrumental region of the plot. The themes are defined as follows:

\section{Expressive}

The expressive theme was comprised of nine behaviors. With the exception of two 'body parts cut off (unskilled)' (50.0\%) and 'severe/extreme force' (41.4\%) - this theme was made up of medium-to-low frequency variables.

These behaviors are characterised by severe-to-extreme levels of physical and sexual violence, therefore indicating body removal in these cases may be motivated by anger or sexual frustration. Victims were more likely to have suffered sharp injury prior to death and were more likely to have experienced sexual penetration. Expressive BPR was more likely to have involved the mutilation or dismemberment of the victim's genitals, breasts or face. Here, BPR was more likely performed using unskilled cuts. 


\section{Instrumental}

The instrumental theme was comprised of 17 behaviors. These included the two most frequent variables - 'multiple wounds (distributed)' (69.0\%) and 'victim naked' $(67.2 \%)$ - as well as the most frequent BPR-specific variable, 'decapitation' $(51.7 \%)$. This theme also included the least frequent variables 'body parts chopped off' and 'victim bound' (both 5.2\%).

Together, the behaviors of this theme indicated offenses that were more goaldirected and functional; with BPR used to facilitate victim disposal and minimise the likelihood of detection. Victims were more likely to have experienced blunt injuries, burns or suffocation during the offense. Offenders were more likely to have brought a weapon to the scene and to have bound their victims. This subtype of BPR was more likely to have involved the mutilation or dismemberment of the victim's head, arms, hands, legs, feet or torso. Here, body parts were most likely sawed or chopped off. Additionally, these cases involved more post-offense behaviors: bodies were discovered naked, hidden, or scattered outdoors and offenders were more likely to have destroyed forensic evidence.

With regards the unexpected presence of 'multiple wounds (distributed)' in the instrumental theme; although this finding opposes those of past research (Salfati \& Haratsis, 2001; Santtila et al., 2001 \& 2003), it is unsurprising given that the presence of multiple wounds is likely an artifact of the process of instrumental BPR. In these cases, the offender is motivated to dispose of the victim's body as effectively as possible by removing and scattering more, often larger, body parts. The infliction of multiple wounds is an unavoidable consequence of this process.

\section{Dominant Theme Analysis}

Thirty-six cases $(62.1 \%)$ of BPR could be classified as a dominant theme, 28 cases (48.3\%) were instrumental, 8 (13.8\%) were expressive and $22(37.9 \%)$ were hybrids. None were non-classifiable.

Chi-square analyses demonstrated a significant difference between the proportion of cases classified as either theme and those classified as hybrids $\left(X^{2}(1\right.$, 58) $=58.00, p<.001, O R=1.62)$. Additionally, a two-tailed Fisher's Exact test showed a significant difference between cases that were dominantly instrumental 
and those that were dominantly expressive $(p=.005, O R=21.53)$. Cases of BPR are therefore 21 times more likely to be as a result of instrumental motivation than expressive motivation.

\section{Discussion}

The study's first objective was to provide base rate frequencies for BPR behaviors. Aside from several high frequency variables - 'body parts cut off (unskilled)', 'head removed' and 'legs or feet removed' - BPR-specific behaviors were medium-to-low frequency, having each occurred in less than $39 \%$ of all cases (Table 5). This suggests that not only is BPR rare in the context of homicide (Di Nunno et al., 2006), but that even within itself, the specific behaviors that constitute the offense are uncommon and widely heterogeneous.

Regarding the second objective, the study conducted a thematic exploration of dismemberment and mutilation murder.. As hypothesised (Table 1), a thematic distinction was made between two subtypes of BPR. 'instrumental' and 'expressive' this typology is consistent with the wider homicide literature (e.g. Salfati \& Canter, 1999).

On closer inspection of the SSA plot (Figure 1), only one of the variables, 'multiple wounds (distributed)', did not fall into its expected location in the expressive theme. Having fallen in the instrumental region instead, its position challenged the findings of previous homicide SSAs (Salfati \& Canter, 1999; Last \& Fritzon, 2005; Salfati \& Dupont, 2006). This discrepancy was reconciled by a simple consideration of the practical constraints involved in instrumental dismemberment. Motivated to dispose of victims as effectively as possible, these offenders dismember their victims more thoroughly - a process in which the infliction of multiple wounds is an unavoidable side-effect. It is therefore logical to consider the behaviour as being instrumental in this context i.e a 'functional' behaviour specifically related to multiple wounds inflicted during the process dismemberment. As such, the observed disparity serves to reiterate the need for researchers and investigators to take into account the context in which offense behaviors occur (see Felson \& Steadman, 1983). 
It was found that $62.1 \%$ could be classified as a dominant theme. Instrumental BPR was most common (48.3\%) and expressive BPR was least common (13.8\%). The higher prevalence of instrumental cases challenged the findings of previous SSAs in which BPR was interpreted as a predominantly expressive behaviour (e.g. Santtila et al., 2001 \& 2003; Canter et al., 2004), whilst supporting the finding that defensive mutilation is more common than offensive (and aggressive) mutilation.

An unexpectedly large proportion of cases (37.9\%) were found to be hybrids of both themes. Why this was found is unclear. However, there are several possible explanations. First, these could represent offenses with a more complex and inconsistent set of underlying motives. Indeed, it has been noted that offenders' motivations can be inconsistent within the act of homicide (Salfati, 2000) - a point which has also been addressed in studies of BPR. Konopka et al. (2007), for example, observed that "in some offensive and aggressive mutilations, the perpetrators additionally dismember the body driven by such motives as defensive mutilation, or - in other words - to remove the corpse or render identification of the victim impossible" (2007, pp. 2). It could be hypothesised that some cases of BPR might represent a phased processwhereby offenders experience a shift in their motivations between the act of murder and the perpetration of post-offense mutilation. This study only examined the motivations for the dismemberment and this may differ from the motivation for the murder itself. Secondly, the number of these cases could have instead been an artefact of the criteria used to assign cases to a dominant theme. Indeed, Salfati (2000) herself described the criteria as "stringent" (pp. 283). Had the study used a less conservative criterion, more cases might have been assigned to a dominant theme.

\section{Limitations and Future Research}

The current study had several limitations. First, although it used the largest sample of any investigation of BPR written in the English language to-date, the sample was nonetheless small. This was unsurprising given the rarity of BPR (Di Nunno et al., 2006) and that the ViCLAS system from which the data was extracted was only established in 1998 . Future research should try to remedy this by using larger samples; whether they use a more complete sample of UK offenses, or a 
combination of contemporary European (or even international) samples. However, it must be acknowledged that the latter is likely to limit the applicability of future findings to investigations of BPR in the UK, although the results may be informative to European/UK based Countries. Future research should consider collecting more diverse samples i.e. how this subset of offenders compares with International samples of BPR and also how they compare with UK homicide offences in general.

Second, the study was limited by its use of secondary data insofar that the researcher had limited control over what was collected. This prevented the study from exploring several offender characteristics that had featured heavily in previous research (such as the developmental and medical histories of offenders) (e.g. Häkkänen-Nyholm et al., 2009). Even where lifestyle variables were included (e.g. 'drug user', 'alcoholic' and 'mental disability'), these should have been interpreted with caution, as the data was not collected or corroborated by medical professionals. Consequently, future research should consider supplementing police data with other sources of biographical information, such as medical, psychiatric and educational records. Despite the obvious practical challenges this would entail, it would allow for a more thorough investigation of BPR. However, it is still recommended that researchers use unobtrusive measures (e.g. archival police records) (see Alison, Snook \& Stein, 2001), since although their collection protocols may not adhere to the highest levels of scientific rigor, they are uncorrupted by researcher bias, and maintain a high level of ecological validity (Canter \& Alison, 2003).

Third, in relation to the high proportion of hybrid cases observed in the study, future research should attempt to explore the relationship between pre- and postoffense behaviors in BPR murder. If it is the case that offenders experience a shift in their motives, then researchers will need to make a conceptual distinction between BPR that occurs before and after the death of the victim. Although this may be operationally difficult to examine, given that dismemberment serves to destroy forensic evidence (Rajs et al., 1998;), the differentiation between pre- and postoffense BPR may prove an important next-step in the development of a comprehensive and internally valid model of BPR. Researchers should also examine the extent to which hybrids are the consequence of the methodology used. In doing so, they should examine how adjustments to the classification criteria affect the overall outcomes of dominant theme analysis. It may be that a less conservative 
methodology is more appropriate for empirical investigations of BPR - although researchers should provide a sound rationale for any changes, and should remain cognisant of the trade-off between Type II and Type I error (Field, 2013).

\section{Conclusion}

This paper has presented the largest study of BPR murder written in the English language to-date and the first to have used both a British sample and a MDS procedure. The study provided base rates and descriptive statistics of BPR offender characteristics, furthering understanding to investigators about those who commit BPR (Cole \& Brown, 2013). It was highlighted that not only is BPR rare within homicides, but the behaviors within the offense are fairly low in frequency, evidencing the difficulties in understanding this crime.

When exploring the behaviors present within a BPR, a SSA identified two behavioural themes (expressive and instrumental) with $62.1 \%$ of cases classified as one of these. The highest proportion was found within the instrumental theme, going against previous work were BPR was seen as a more expressive behaviour. Due to this finding, and the large number of hybrids found, the notion of a 'phased process' reflecting the possible changes in offender motivation from the act of murder to the mutilation, requires further understanding. Exploring of baseline behaviors within BPR and the behavioural model produced provide further understanding for academic research and criminal investigations of BPR in the UK. 


\section{APPENDIX-CODING DICTIONARY}

\begin{tabular}{|c|c|}
\hline Offense Behaviour & Description \\
\hline Decapitation & The victim's head was removed and/or their neck was mutilated. \\
\hline Face mutilated & $\begin{array}{l}\text { The victim's face was mutilated. This also included the removal } \\
\text { of the victim's eyes or nose. }\end{array}$ \\
\hline Arms/hands removed & The victim's arms and/or hands were removed. \\
\hline Torso mutilated & $\begin{array}{l}\text { The victim's torso was mutilated. This also included the } \\
\text { mutilation of the victim's chest, back, shoulder and/or abdomen. }\end{array}$ \\
\hline Breasts removed & The victim's breasts were removed. \\
\hline Genitalia removed & The victim's genitals were removed. \\
\hline Legs/feet removed & The victim's legs and/or feet were removed. \\
\hline Body parts cut off (unskilled) & The victim's body parts were cut off using unskilled incisions. \\
\hline Body parts sawed off & The victim's body parts were sawed off. \\
\hline Body parts chopped off & The victim's body parts were chopped off. \\
\hline Body parts scattered & The victim's body parts were scattered. \\
\hline Weapon brought & The offender brought a weapon to the scene of the offense. \\
\hline Sharp injury & $\begin{array}{l}\text { The victim suffered pre-mortem sharp injury. This included } \\
\text { cases where the victim was cut, had their hair cut, was stabbed, } \\
\text { had their throat slashed, experienced other sharp injury and/or } \\
\text { experienced sharp injury by way of an unknown method. }\end{array}$ \\
\hline Blunt injury & $\begin{array}{l}\text { The victim suffered pre- and/or post-mortem blunt injury. This } \\
\text { included cases where the victim was crushed, bitten, hit with } \\
\text { hands and/or objects, had their hair pulled, was kicked, } \\
\text { experienced other blunt injury and/or experienced blunt injury by } \\
\text { way of an unknown method. }\end{array}$ \\
\hline Burn injury & $\begin{array}{l}\text { The victim suffered pre- and/or post-mortem burns. This } \\
\text { included cases where the victim was burned using a flame, was } \\
\text { scalded, suffered electrical burns and/or experienced burns by } \\
\text { other means. }\end{array}$ \\
\hline Suffocation & $\begin{array}{l}\text { The victim was suffocated pre- and/or post- mortem. This } \\
\text { included cases where the victim was suffocated manually, using } \\
\text { a ligature, strangled, drowned and/or by way of an unknown } \\
\text { method. }\end{array}$ \\
\hline Multiple wounds & The victim suffered wounds to more than one body part. \\
\hline Severe/extreme force & The victim suffered severe and/or extreme levels of violent force. \\
\hline Violence to genitalia & The victim suffered harm to their genitals and/or groin. \\
\hline Vaginal penetration & $\begin{array}{l}\text { The victim's vagina was penetrated. This included penetration } \\
\text { by penis, finger, hand, foreign object and/or unknown method. }\end{array}$ \\
\hline Anal penetration & $\begin{array}{l}\text { The victim's anus was penetrated. This included penetration by } \\
\text { penis and/or foreign object. }\end{array}$ \\
\hline Victim naked & $\begin{array}{l}\text { The victim was naked. This included cases where the victim was } \\
\text { partially or completely disrobed, or had their clothing moved to } \\
\text { expose. }\end{array}$ \\
\hline Victim bound & $\begin{array}{l}\text { The victim was bound. This also included cases where the victim } \\
\text { was blindfolded and/or gagged. }\end{array}$ \\
\hline Forensics destroyed & The offender destroyed forensic material. \\
\hline Body discovered outdoors & The victim's body and/or body parts were discovered outdoors. \\
\hline Body hidden & $\begin{array}{l}\text { The victim's body and/or body parts were hidden. This included } \\
\text { cases where the body was discovered partially or completely } \\
\text { concealed, partially or completely buried, partially immersed, } \\
\text { weighted or unweighted in water, or found in a box or vehicle. }\end{array}$ \\
\hline
\end{tabular}




\section{References}

Alison, L., Smith, M., Eastman, O., \& Rainbow, L. (2003). Toulmin's philosophy of argument and its relevance to offender profiling. Psychology, Crime \& Law, 9(2), 173-183. DOI:10.1080/1068316031000116265

Alison, L., Snook, B., \& Stein, K. (2001). Unobtrusive measurement: Using police information for forensic research. Qualitative Research, 1(2), 241-254. DOI:10.1177/146879410100100208

Almond, L., Alison, L. \& Porter, L. (2008). An evaluation and comparison of claims made in Behavioural Investigative Advice reports compiled by the National Policing Improvements Agency in the United Kingdom. Journal of Investigative Psychology and Offender Profiling, 4, 71-83.

Bhootra, B., \& Weiss, E. (2006). Muti killing: A case report. Medicine, Science and the Law, 46(3), 255-259. Retrieved from http://journals.sagepub.com

Bland, J., \& Altman, D. (1995). Multiple significance tests: The Bonferroni method. British Medical Journal, 310, 170. DOI:10.1136/bmj.310.6973.170

Bonny, E., Almond, L., \& Woolnough, P. (2016). Adult missing persons: Can an investigative framework be generated using behavioural themes? Journal of Investigative Psychology and Offender Profiling, 13(3), 296-312. DOI:10.1002/jip.1459

Borg, I., \& Lingoes, J. (1987). Multidimensional similarity structure analysis. New York: Springer-Verlag

Campbell, D., \& Stanley, J. (1966). Experimental and quasi-experimental designs for research. Boston, MA: Houghton Mifflin

Canter, D., \& Alison, L. (2003). Converting evidence into data: The use of law enforcement archives as unobtrusive measurement. The Qualitative Report, 8(2), 151-176. Retrieved from http://nsuworks.nova.edu

Canter, D., \& Heritage, R. (1990). A multivariate model of sexual offense behaviour: Developments in 'offender profiling'. The Journal of Forensic Psychiatry, 1(2), 185-212. DOI:10.1080/09585189008408469 
Canter, D., Alison, L., Alison, E., \& Wentink, N. (2004). The organized/disorganized typology of serial murder: Myth or model? Psychology, Public Policy, and Law, 10(3), 293-320. DOI:10.1037/1076-8971.10.3.293

Chinn, S. (2000). A simple method for converting an odds ratio to effect size for use in meta-analysis. Statistics in Medicine, 19(22), 3127-3131.

DOI:10.1002/1097-0258(20001130)19:22<3127::AID-SIM784>3.0.CO;2-M

Cole, T., \& Brown, J. (2013). Behavioural investigative advice: Assistance to investigative decision-making in difficult-to-detect murder. Investigative Psychology and Offender Profiling, 11(3), 191-220. DOI:10.1002/jip.1396

Cox, J. (2006). Dismemberment \& mutilation murder: A thematic exploration. (Unpublished undergraduate dissertation). University of Bath, United Kingdom

Cozby, P., \& Bates, S. (2012). Methods in Behavioral Research. (11th ed.). New York, NY: McGraw-Hill

Di Nunno, N., Costantinides, F., Vacca, M., \& Di Nunno, C. (2006). Dismemberment: A review of the literature and description of 3 cases. The American Journal of Forensic Medicine and Pathology, 27(4), 307-312.

DOI:10.1097/01.paf.0000188170.55342.69

Felson, R., \& Steadman, H. (1983). Situational factors in disputes leading to criminal violence. Criminology, 21(1), 59-74. DOl:10.1111/j.1745-9125.1983.tb00251.x

Feshbach, S. (1964). The function of aggression and the regulation of aggressive drive. Psychological Review, 71(4), 257-272. DOI:10.1037/h0043041

Field, A. (2013). Discovering statistics using IBM SPSS statistics: And sex and drugs and rock 'n' roll. (4th ed.). London, UK: Sage

Goodwill, A., Alison, L., \& Humann, M. (2009). Multidimensional scaling and the analysis of sexual offense behaviour: A reply to Sturridsson et al. Psychology, Crime \& Law, 15(6), 517-524. DOI:10.1080/10683160802348511

Guttman, L. (1968). A general nonmetric technique for finding the smallest coordinate space for a configuration of points. Psychometrika, 33(4), 469-506. Retrieved from https://link.springer.com 
Häkkänen-Nyholm, H., Weizmann-Henelius, G., Salenius, S., Lindberg, N., \& RepoTiihonen, E. (2009). Homicides with mutilation of the victim's body. Journal of Forensic Sciences, 54(4), 933-937. DOI:10.1111/j.1556-4029.2009.01094.x

Hejna, P., Šafr, M., \& Zátopková, L. (2012). Suicidal decapitation by guillotine: Case report and review of the literature. Journal of Forensic Sciences, 57(6), 16431645. DOI:10.1111/j.1556-4029.2012.02153.x

Karakasi, M., Vasilikos, E., Voultsos, P., Vlachaki, A., \& Pavlidis, P. (2017). Sexual homicide: Brief review of the literature and case report involving rape, genital mutilation and human arson. Journal of Forensic and Legal Medicine, 46, 1-10. DOI:10.1016/j.jflm.2016.12.005

Keppel, R., \& Walter, R. (1999). Profiling killers: A revised classification model for understanding sexual murder. International Journal of Offender Therapy and Comparative Criminology, 43(4), 417-437. DOI:10.1177/0306624X99434002

Konopka, T., Strona, M., Bolechala, F., \& Kunz, J. (2007). Corpse dismemberment in the material collected by the Department of Forensic Medicine, Cracow, Poland. Legal Medicine, 9(1), 1-13. DOI:10.1016/j.legalmed.2006.08.008

Last, S., \& Fritzon, K. (2005). Investigating the nature of expressiveness in stranger, acquaintance and intrafamilial homicides. Journal of Investigative Psychology and Offender Profiling, 2(3), 179-193. DOI:10.1002/jip.36

Law, J. (2015). Homicide. In A Dictionary of Law (8 $8^{\text {th }}$ ed.). DOI:10.1093/acref/9780199664924.001.0001

Leech, C., \& Porter, K. (2016). Man or machine? An experimental study of prehospital emergency amputation. British Medical Journal, 33(9), 1-4. DOI:10.1136/emermed-2015-204881

Lingoes, J. (1973). The Guttman-Lingoes non-metric program series. (Published Master's thesis). University of Michigan, MI.

Maxwell, S., Lau, M., \& Howard, G. (2015). Is psychology suffering from a replication crisis? What does "failure to replicate" really mean? American Psychologist, 70(6), 487-498. DOI:10.1037/a0039400 
Office for National Statistics. (2016). Compendium: Homicide. Retrieved on 22/12/2016 from www.ons.gov.uk

Rajs, J., Lundstrom, M., Broberg, M., Lidberg, L., \& Lindquist, O. (1998). Criminal mutilation of the human body in Sweden - A thirty-year medico-legal and forensic psychiatric study. Journal of Forensic Sciences, 43(3), 563-580. DOI:10.1520/JFS16183J

Ressler, R., Burgess, A., Hartman, C., Douglas, J., \& McCormack, A. (1986). Murderers who rape and mutilate. Journal of Interpersonal Violence, 1(3), 273-287. Retrieved from http://journals.sagepub.com

Reuhl, J., \& Bratzke, H. (1999). Death caused by a chain saw - homicide, suicide or accident?: A case report with a literature review (with 11 illustrations). Forensic Science International, 105(1), 45-59.

DOI:10.1016/S0379-0738(99)00096-1

Rosenthal, R. (1991). Meta-analytic procedures for social research. (2nd ed.). Newbury Park, CA: Sage

Rosnow, R., \& Rosenthal, R. (1989). Statistical procedures and the justification of knowledge in psychological science. American Psychologist, 44(10), 1276-1284. DOI:10.1037/0003-066X.44.10.1276

Salfati, C. (2000). The nature of expressive and instrumentality in homicide: Implications for offender profiling. Homicide Studies, 4(3), 265-293. DOI:10.1177/1088767900004003004

Salfati, C. (2003). Offender interaction with victims in homicide: A multidimensional analysis of frequencies in crime scene behaviors. Journal of Interpersonal Violence, 18(5), 490-512. DOI:10.1177/0886260503251069

Salfati, C., \& Taylor, P. (2006) Differentiating sexual violence: A comparison of sexual homicide and rape. Psychology, Crime \& Law, 12(2), 107-125, DOI:10.1080/10683160500036871

Salfati, C., \& Bateman, A. (2005). Serial homicide: An investigation of behavioural consistency. Journal of Investigative Psychology and Offender Profiling, 2(2), 121-144. DOI:10.1002/jip.27 
Salfati, C., \& Canter, D. (1999). Differentiating stranger murders: Profiling offender characteristics from behavioral styles. Behavioral Sciences and the Law, 17(3), 391-406. DOI:10.1002/(SICI)1099-0798(199907/09)17:33.0.CO;2-Z

Salfati, C., \& Dupont, F. (2006). Canadian homicide: An investigation of crime-scene actions. Homicide Studies, 10(2), 118-139.

DOI:10.1177/1088767906288449

Salfati, C., \& Haratsis, E. (2001). Greek homicide: A behavioral examination of offender crime-scene actions. Homicide Studies, 5(4), 335-362. DOI:10.1177/1088767901005004006

Santtila, P., Canter, D., Elfgren, T., \& Häkkänen, H. (2001). The structure of crimescene actions in Finnish homicides. Homicide Studies, 5(4), 363-387. DOI:10.1177/1088767901005004007

Santtila, P., Häkkänen, H., Canter, D., \& Elfgren, T. (2003). Classifying homicide offenders and predicting their characteristics from crime scene behavior. Scandinavian Journal of Psychology, 44(2), 107-118. DOI:10.1111/1467-9450.00328

Scholtz, H., Phillips, V., \& Knobel, G. (1997). Muti or ritual murder. Forensic Science International, 87(2), 117-123. DOI:10.1016/S0379-0738(97)02132-4

Steyn., M. (2005). Muti murders form South Africa: A case report. Forensic Science International, 151(2-3), 279-287. DOI:10.1016/j.forsciint.2004.05.022

Tavakol, M., \& Dennick, R. (2011). Making sense of Cronbach's alpha. International Journal of Medical Education, 2, 53-55. DOI:10.5116/ijme.4dfb.8dfd

Thijssen, J., \& de Ruiter, C. (2011). Instrumental and expressive violence in Belgian homicide perpetrators. Journal of Investigative Psychology and Offender Profiling, 8(1), 58-73. DOI:10.1002/jip.130

Türk, E., Püschel, K., \& Tsokos, M. (2004). Features characteristic of homicide in cases of complete decapitation. American Journal of Forensic Medicine and Pathology, 25(1), 83-86. DOI:10.1097/01.paf.0000113921.06940.1d 